Research Article:

\title{
The Frequency of Human Leukocyte Antigen Class I and II Alleles and the Relationship Between Haplotypes in Gilaks Population of Iran
}

\author{
Mansour Arab $^{1}$ (D), Zahra Pourpak ${ }^{1}$ (D), Sajedeh Mohammadian', Ahad Zare² ${ }^{2}$, Yadollah Shakiba ${ }^{3}$, Raheleh Shokouhi Shoormasti ${ }^{1}$ (D) Mah- $^{-}$ \\ di Jalilit, Mohammad Reza Fazlollahi' $^{1}$ (D), Mostafa Moin ${ }^{1}$, Maryam Nourizadeh ${ }^{*}$ (D) \\ 1. Immunology Asthma and Allergy Research Institute, Tehran University of Medical Sciences, Tehran, Iran. \\ 2. Department of Microbiology and Immunology, Faculty of Medicine, Tehran Medical Sciences, Islamic Azad University, Tehran, Iran. \\ 3. Regenerative Medicine Research Center, Kermanshah University of Medical Sciences, Kermanshah, Iran. \\ 4. Hematology Oncology and Stem Cell Research Center, Tehran University of Medical Sciences, Tehran, Iran.
}

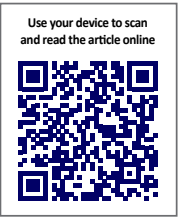

Cftation Arab M, Pourpak Z, Mohammadian S, Zare A, Shakiba Y, Shokouhi Shoormasti R, et al. The Frequency of Human Leukocyte Antigen Class I and II Alleles and the Relationship Between Haplotypes in Gilaks Population of Iran. Immunoregulation. 2019; 2(1):57-66. http://dx.doi.org/10.32598/Immunoregulation.1.3.175

dol' http://dx.doi.org/10.32598/Immunoregulation.1.3.175

Article info:

Received: 20 Apr 2018

Accepted: 28 Aug 2018

Available Online: 01 July 2019

Keywords:

Human Leukocyte

Antigen, Classes I and

II, Gilak ethnicity, Gilan

Province

\begin{abstract}
A B S T RA C T
Background: The Human Leukocyte Antigen (HLA) is the most polymorphic region in human genome. Moreover, HLA haplotype frequencies are largely used in transplantation, the treatment of autoimmune diseases, and population-based studies. The present study aimed to determine HLA-A, -B, -DR alleles and haplotype frequencies in 88 unrelated donors of Iranian Gilak ethnic group, by Polymerase Chain Reaction with Sequence-Specific Primer (PCR-SSP) assay. The study findings were compared with previous reports on HLA alleles of different Iranian ethnics.

Materials and Methods: The blood samples were collected from 88 donors of the Gilak ethnicity. Deoxyribonucleic Acid (DNA) of the samples were extracted. Then, we performed PCR and electrophoresis. The frequency of different alleles was analyzed using software.

Results: Our obtained results suggested that the most frequent alleles for HLA-A were $A * 02$ (24.4\%), $\mathrm{A} * 11(17.6 \%)$, and $\mathrm{A} * 03(14.2 \%)$, and the same for HLA-B were B*35 (26.7\%), B*51 (12.5\%), and $\mathrm{B} * 52(11.4 \%)$, and for HLA-DRB1 were DRB1*11 (14.1\%), DRB1*01 (13.5\%), and DRB1*04 $(11.8 \%)$. In addition, the most common three-locus haplotypes were A02:B35:DRB01 (9.1\%), A68:B49:DRB14 (6.2\%), and A11:B51:DRB04 (5.1\%) among the studied group.
\end{abstract}

Conclusion: Despite some differences, we found a strong relationship in the allelic variation between Gilak ethnicity and other Iranian and Caucasians ethnics.

\footnotetext{
* Corresponding Author:

Maryam Nourizadeh, PhD.

Address: Immunology Asthma and Allergy Research Institute, Tehran University of Medical Sciences, Tehran, Iran.

Phone: +98 (21) 66938545

E-mail: nourizadeh.maryam@gmail.com
} 


\section{Introduction}

$\mathbf{T}$

he Human Leukocyte Antigen (HLA) is a highly polymorphic locus in the human genome with two major classes of I (HLAA, HLA-B, and HLA-C) and II (HLA-DR, $\mathrm{DQ}$, and DP) [1]. The HLA plays a key role in discrimination between self and nonself antigens in different aspects of the immune responses. It is effective against infectious agents, in autoimmune reactions, in organ or stem cell transplantation, and vaccine development $[2,3]$. A Mendelian inheritance exists in HLA haplotypes from each parent. Thus, there are comparative studies on haplotype frequencies between different ethnics and races. Therefore, HLA typing not only provides a powerful tool for anthropological studies, but also a clear insight regarding the genetic relations and a degree of admixture within the populations $[1,4,5]$. Considering the extensive invasions and migrations assigned to Macedonians, Arabs, Tatars, Turks, and Mongols, Iran is a great mixed-race society of Caucasian and others [2].

Phylogenetic analyses suggested that Iranians have HLA similarities with the Southwestern countries like Greek and Southern Europe countries like Italy $[2,6]$. There are different ethnic groups among Iranian people, including Persian, Turk, Kurd, Lure, Lak, Turkman, Arab, Zaboli, Bakhtiari, Baloch, Zoroastrian, Jew, Armenian, Assyrian and so on [2, 4, 7-9]. The regional frequencies of HLA alleles have previously reported unusual racial variations in the Iranian population in Mashhad City, Iran [4].
Gilan Province is located between the Caspian sea and Alborz mountain range in Northern Iran (Figure 1). Regarding a considerable distance between Gilan and the ancient race-mixing incidence, its population, known as Gilak, has remained pretty pure. To our knowledge, this is the first analysis report of HLA A, B, and DR alleles, and haplotype frequency among Gilaks. This could be part of addressing data gaps in the literature on all regions and races in Iran.

\section{Materials and Methods}

Blood samples were collected from 88 unrelated Gilak healthy donors, who were originated from Gilan, living in either Tehran or Gilan provinces. They had been registered in the HLA bank of Immunology, Allergy and Asthma Research Institute. The mean age of the study participants was 39.09 years (ranged from 15 to 69 years). Blood samples $(5 \mathrm{~mL})$ were collected in EDTA tubes. DNA of each sample was extracted using DNA extraction kit (Roche, Basel, Switzerland).

HLA-A, B, DRB1 were typed in a two-digit format by Polymerase Chain Reaction with Sequence-Specific Primer (PCR-SSP) method using Olerup SSP kits (Olerup SSP, Stockholm, Sweden), according to the manual for low-resolution typing. Taq polymerase was purchased from Roche (Basel, Switzerland). The samples were amplified in thermal cyclers (SimpliAmp, Applied Biosystems, USA) according to the following procedure:

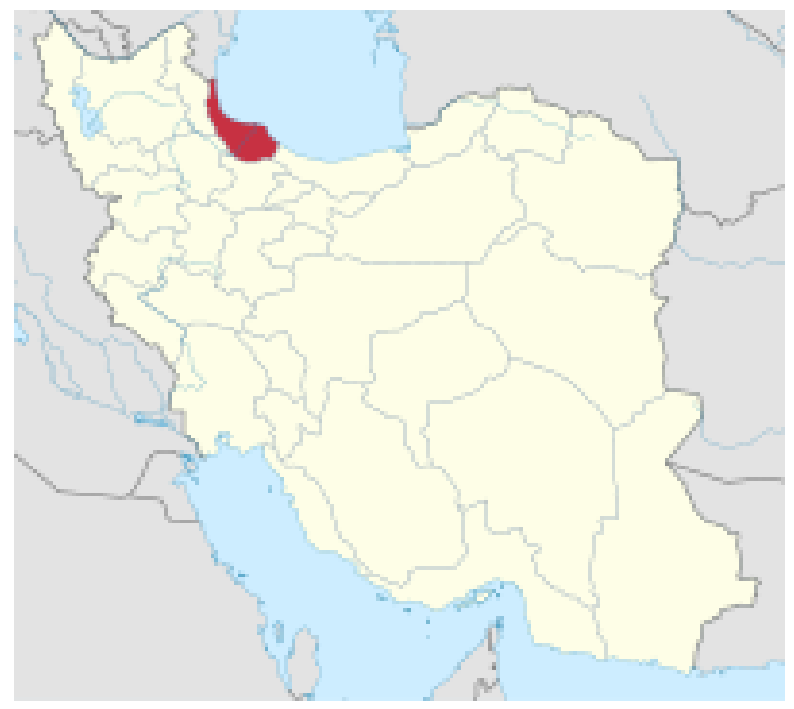

Figure 1. Geolocation of Gilan Province in Iran

IMMUNoREgGLATIO) 


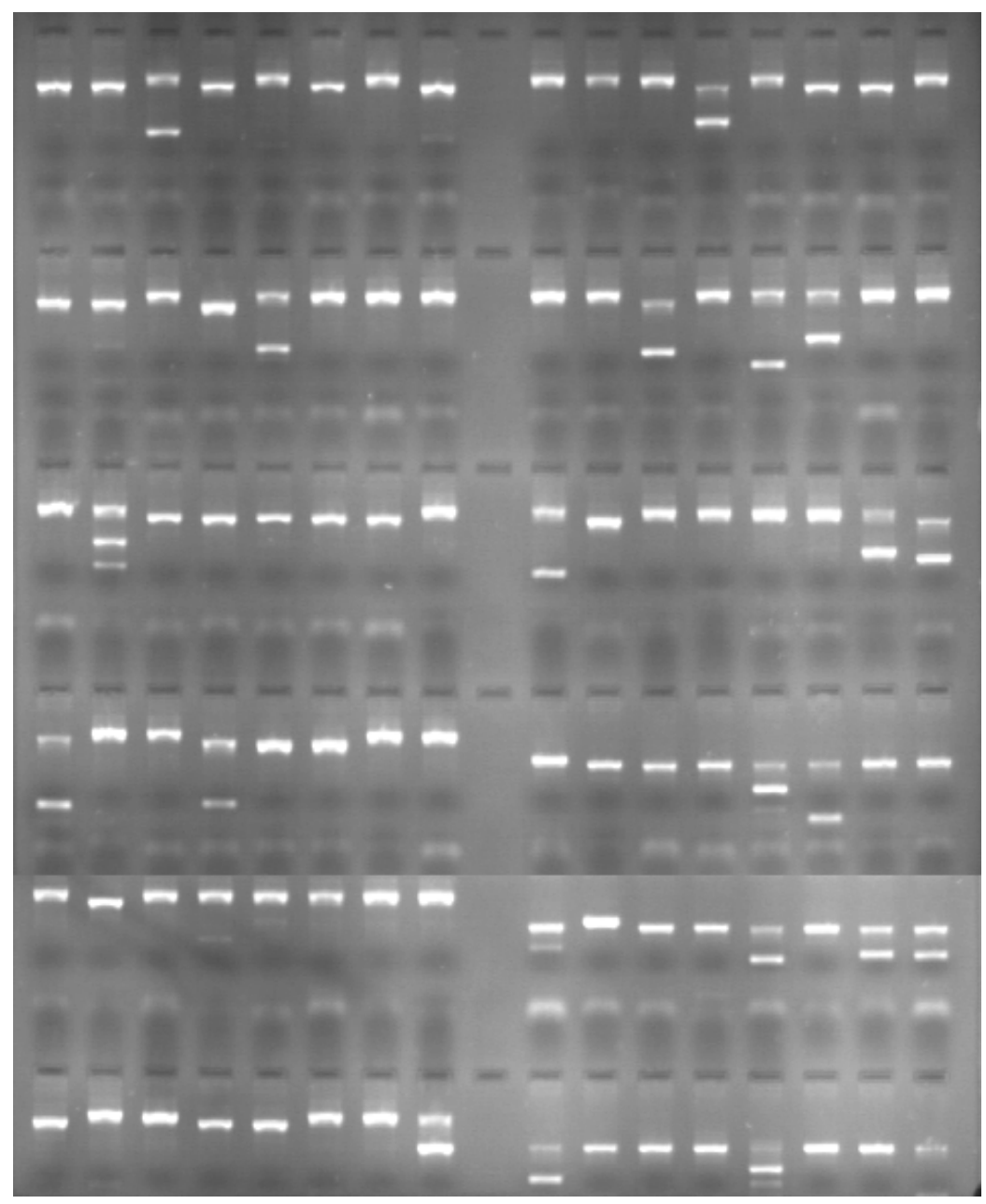

Figure 2. Phenotypes of HLA-ABDR locus

IminunoRegulation

1. 1 cycle $94^{\circ} \mathrm{C} 2$ min denaturation

2. 10 cycles $94^{\circ} \mathrm{C} 10 \mathrm{sec}$ denaturation

$65^{\circ} \mathrm{C} 60 \mathrm{sec}$ annealing and extension

3. 20 cycles $94^{\circ} \mathrm{C} 10 \mathrm{sec}$ denaturation

$61^{\circ} \mathrm{C} 50 \mathrm{sec}$ annealing

$72^{\circ} \mathrm{C} 30$ sec extension

Finally, the PCR products were analyzed using agarose gel electrophoresis on a $2 \%$ agarose gel and stained with safe green dyes (Figure 2). Alleles were analyzed using the specific software provided by the Olerup company. The frequencies of A, B, and DR alleles, as the representatives of HLA classes I and II were determined using SPSS. The neighbor-joining dendrogram was drawn in $\mathrm{R}$ program $=$.

\section{Results}

In this study, HLA-A, -B, and -DRB1 percentages were $6.88(6.8 \%), 12.88(13.6 \%)$, and $7.85(1.17 \%)$, respectively. The most frequent HLA-A and -B alleles were $* 02$ and $* 35$, respectively. These alleles were detected in almost one-fourth of the samples (Table 1). Although DRB1*11 was found in $14.1 \%$ of the individuals, it was not as common as $\mathrm{A}^{*} 02$ and $\mathrm{B}^{*} 35$ alleles.

The remaining alleles, including $\mathrm{A}^{*} 11(17.6 \%)$ and $A * 03(14.2 \%)$ for $\mathrm{A}, \mathrm{B} * 51(12.5 \%)$ and $\mathrm{B} * 52(11.4 \%)$ for $\mathrm{B}$, as well as DRB1*01 (13.5\%), and DRB1*04 $(11.8 \%)$, for DRB1, were also observed as the second and third common allelic expressions among Gilaks. Moreover, HLA-A*29, A*31, A*33, and A*66 (1\%), HLA-B *44, B*73 (1\%), and HLA-DRB1*12 (3.5\%), were the least frequent alleles. The haplotype frequencies were obtained by calculating the linkages between some alleles using Arlequin (Table 2). 
Table 1. Frequency of HLA-A, -B, DRB1 alleles in individuals originally from Gilac ethnicity, Iran

\begin{tabular}{|c|c|c|c|c|c|}
\hline HLA-A* Alleles & $\begin{array}{c}F(\%) \\
N=176\end{array}$ & HLA-B* Alleles & $\begin{array}{c}F(\%) \\
N=176\end{array}$ & HLA-DRB1* Alleles & $\begin{array}{c}F(\%) \\
N=170\end{array}$ \\
\hline 1 & $6(3.4)$ & 7 & $7(4.0)$ & 1 & $23(13.5)$ \\
\hline 2 & $43(24.4)$ & 8 & $4(2.3)$ & 3 & $16(9.4)$ \\
\hline 3 & $25(14.2)$ & 13 & $3(1.7)$ & 4 & $20(11.8)$ \\
\hline 11 & $31(17.6)$ & 14 & $5(2.8)$ & 7 & $11(6.5)$ \\
\hline 23 & $2(1.1)$ & 18 & $4(2.3)$ & 8 & $1(0.6)$ \\
\hline 24 & $21(11.9)$ & 27 & $6(3.4)$ & 10 & $11(6.5)$ \\
\hline 26 & $16(9.1)$ & 35 & $47(26.7)$ & 11 & $24(14.1)$ \\
\hline 29 & $1(0.6)$ & 37 & $5(2.8)$ & 12 & $6(3.5)$ \\
\hline 30 & $5(2.8)$ & 38 & $3(1.7)$ & 13 & $9(5.3)$ \\
\hline 31 & $1(0.6)$ & 40 & $10(5.7)$ & 14 & $19(11.2)$ \\
\hline 32 & $6(3.4)$ & 41 & $4(2.3)$ & 15 & $17(10.0)$ \\
\hline 33 & $1(0.6)$ & 44 & $1(0.6)$ & 16 & $13(7.6)$ \\
\hline 66 & $1(0.6)$ & 49 & $16(9.1)$ & & \\
\hline \multirow[t]{6}{*}{68} & $17(9.7)$ & 50 & $6(3.4)$ & & \\
\hline & & 51 & $22(12.5)$ & & \\
\hline & & 52 & 20(11.4) & & \\
\hline & & 55 & $9(5.1)$ & & \\
\hline & & 57 & $3(1.7)$ & & \\
\hline & & 73 & $1(0.6)$ & & \\
\hline
\end{tabular}

IMMUNOREGLLATION

It was performed to explore the probability of simultaneous expression in the observed alleles. The most common haplotypes forms belonged to A02:B35:DRB01 (9.1\%). However, A68:B49:DRB14 (6.25\%) and A11:B51:DRB04 (5.11\%), were respectively observed as the second and third frequent haplotypes. Moreover, the remaining combinations did not have a considerable prevalence among Gilak ethnic group.

\section{Discussion}

We investigated the frequency of HLA-A, -B and -DRB1 alleles as well as the related haplotypes among Gilak population. The subjects were registered as unrelated volunteer donors by the HLA bank of Immunology, Allergy, and Asthma Research Institute.
Of the 88 sequenced individuals, HLA-A*02 (24.4\%), -B*35 (26.7\%), and -DRB1*11 (14.1\%), were identified as the most frequent alleles (Figures $3 \& 4$ ). This finding is similar in other Iranian ethnicities. However, there were also differences that were due to the integration of these races with other communities throughout the centuries. In most studies, HLA-A*02, -B*35, and -DRB1*11 were identified as the most abundant alleles in Iran $[2,5,8-10]$.

Iran has a distinguished geographic location and linked Europe and Asia by the Silk Road [2]. Although the origins of Iranians are Caucasian, different tribes have been settled down here through various migrations and invasions [2, 4, 7-9]. Comparing Gilak ethnic with other populations, and drawing the phylogenetic tree and corresponding analysis suggests that Gilak ethnic is in 
Table 2. The most frequent three-locus haplotypes in Gilak ethnicity of Iran

\begin{tabular}{|c|c|}
\hline Haplotype & HF (\%) \\
\hline A02:B35:DRB01 & 9.1 \\
\hline A68:B49:DRB14 & 6.25 \\
\hline A11:B51:DRB04 & 5.11 \\
\hline A02:B52:DRB15 & 2.84 \\
\hline A03:B52:DRB15 & 2.84 \\
\hline A01:B37:DRB03 & 2.28 \\
\hline A03:B07:DRB10 & 2.28 \\
\hline A11:B35:DRB11 & 2.28 \\
\hline A11:B51:DRB07 & 2.28 \\
\hline A24:B55:DRB11 & 2.28 \\
\hline A26:B52:DRB11 & 2.28 \\
\hline A11:B18:DRB11 & .7 \\
\hline A03:B14:DRB03 & 1.7 \\
\hline A24:B08:DRB03 & 1.7 \\
\hline A24:B40:DRB14 & 1.7 \\
\hline A26:-:DRB16 & 1.7 \\
\hline A26:B35:DRB16 & 1.7 \\
\hline A68:B55:DRB13 & 1.7 \\
\hline A02:B27:DRB10 & 1.1 \\
\hline A02:B35:- & 1.1 \\
\hline A02:B41:DRB04 & 1.1 \\
\hline A02:B50:DRB13 & 1.1 \\
\hline A02:B51:DRB10 & 1.1 \\
\hline A02:B55:DRB12 & 1.1 \\
\hline A03:B35:DRB11 & 1.1 \\
\hline A03:B35:DRB12 & 1.1 \\
\hline A03:B50:DRB07 & 1.1 \\
\hline A11:B51:DRB11 & 1.1 \\
\hline A11:B52:DRB01 & 1.1 \\
\hline A23:B49:DRB15 & 1.1 \\
\hline A24:B52:DRB15 & 1.1 \\
\hline
\end{tabular}


Table 3. Frequency of HLA-A alleles in Gilak ethnic group in comparison to total Iranian population

\begin{tabular}{|ccc|}
\hline HLA-A* Alleles & In Gilak Population (F\%) & In Total Iranian Population (F\%) [8] \\
\hline 01 & 3.4 & 9.25 \\
\hline 2 & 24.4 & 18.16 \\
\hline 03 & 14.2 & 12.08 \\
\hline 11 & 17.6 & 10.41 \\
\hline 23 & 1.1 & 2.25 \\
\hline 24 & 11.9 & 16.14 \\
\hline 26 & 9.1 & 6.83 \\
\hline 29 & 0.6 & 2.5 \\
\hline 30 & 2.8 & 4.66 \\
31 & 0.6 & 6.16 \\
32 & 3.4 & 5.66 \\
\hline 33 & 0.6 & - \\
\hline 6 & 0.6 & 3.66 \\
\hline 68 & 9.7 & 0.25 \\
\hline
\end{tabular}

IMMUNoReGULATION

Table 4. Frequency of HLA-B alleles in Gilak ethnic group in comparison to total Iranian population

\begin{tabular}{|c|c|c|}
\hline HLA-B* Alleles & In Gilak Population (F\%) & In Total Iranian Population (F\%) [8] \\
\hline 07 & 4.0 & 4.75 \\
\hline 08 & 2.3 & 4.25 \\
\hline 13 & 1.7 & 3.91 \\
\hline 14 & 2.8 & 3.00 \\
\hline 18 & 2.3 & 4.33 \\
\hline 27 & 3.4 & 2.58 \\
\hline 35 & 26.7 & 21.66 \\
\hline 37 & 2.8 & 1.00 \\
\hline 38 & 1.7 & 4.33 \\
\hline 40 & 5.7 & 3.58 \\
\hline 41 & 2.3 & 2.75 \\
\hline 44 & 0.61 & 4.16 \\
\hline 49 & 9.1 & - \\
\hline 50 & 3.4 & 3.58 \\
\hline 51 & 12.5 & 13.33 \\
\hline 52 & 11.4 & 3.5 \\
\hline 55 & 5.1 & 0.35 \\
\hline 57 & 1.7 & 1.00 \\
\hline 58 & 0.6 & 1.91 \\
\hline
\end{tabular}


Table 5. The allele frequency of HLA-ABDR in Gilak population compared to different populations

\begin{tabular}{|c|c|c|c|c|c|c|c|}
\hline HLA & Gilak & $\begin{array}{c}\text { Fars } \\
{[6]}\end{array}$ & $\begin{array}{c}\text { Bakhtiyari } \\
{[18]}\end{array}$ & $\begin{array}{c}\text { Yazd } \\
{[2]}\end{array}$ & $\begin{array}{c}\text { Mashhad } \\
\text { [4] }\end{array}$ & $\begin{array}{c}\text { Greece } \\
\text { [19] }\end{array}$ & $\begin{array}{c}\text { Macedonia } \\
\text { [20] }\end{array}$ \\
\hline DRB1*01 & 13.5 & 5.5 & 8 & 8.8 & 7.5 & 6.3 & 5.2 \\
\hline DRB1*03 & 9.4 & 10 & 10 & 8.8 & 8.7 & 10.4 & 9 \\
\hline DRB1*04 & 11.8 & 10.5 & 12 & 7.2 & 12.5 & 7.1 & 7.9 \\
\hline DRB1*07 & 6.5 & 6.5 & 12 & 13.3 & 15 & 6.7 & 6.4 \\
\hline DRB1*10 & 6.5 & 4 & 5 & 2.7 & - & 2.5 & 2 \\
\hline DRB1*11 & 14.1 & 25 & 16 & 24.4 & 24.8 & 15 & 24.8 \\
\hline DRB1*15 & 10.0 & 12 & 14 & 13.3 & 11.9 & 20 & 11.9 \\
\hline
\end{tabular}

IminoRegilation
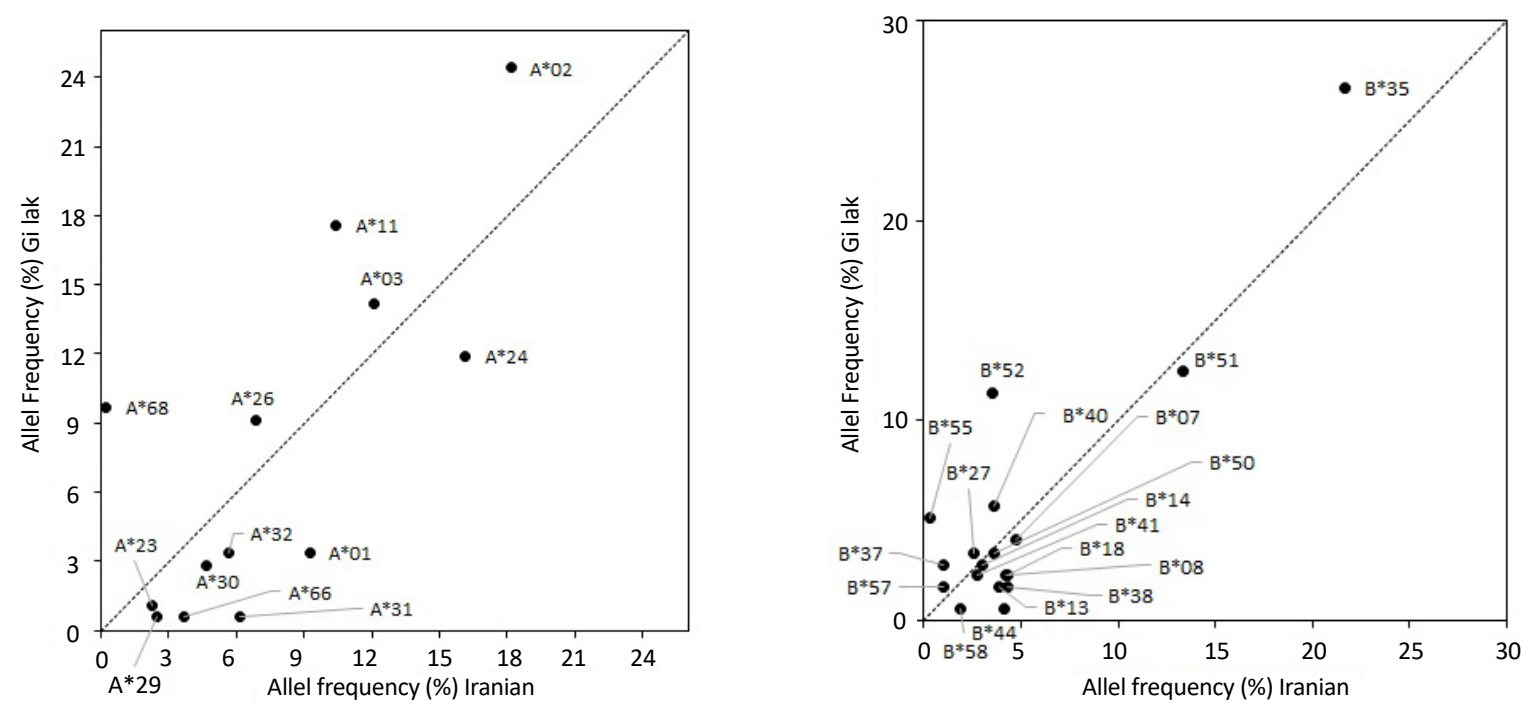

IMMUNoRegulation

Figure 3. Comparison of imputed HLA allele frequencies between Gilak population with other Iranian ethnics Correlation was seen (for HLA-A, 0.761 for HLA-B, 0.885).

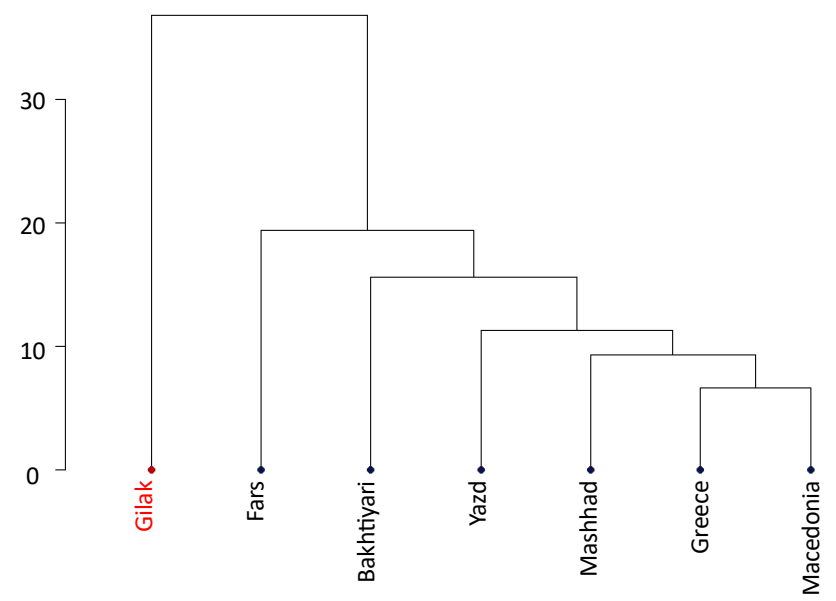

IMMUNoRegulation

Figure 4. Neighbor-joining dendrograms, showing relatedness between Gilak and other populations using generic HLADRB1*01 allele frequencies data 
close vicinity with other Iranian ethnic groups, as well as Macedonians and Greeks (Figures 3 and 4).

Gilan is a Northern province of Iran, surrounded by the Alborz Mountains in the south and the Caspian sea in the north. The presence of these natural obstructions has greatly hindered the combination of this ethnic with others. This is the fact that makes studying this ethnic attractive. HLA polymorphism studies of various Iranian populations reported numerous changes. For example, in some regions of Iran, another allele for HLA-DRB1 was reported as the most abundant allele. DRB $1 * 15$ in Mashhad [4], DRB1*07 in Arabs residing in Khuzestan and Zoroastrians in Yazd [7], DRB1*03 and DR2 in Baloch tribes residing in Sistan and Baluchistan province $[9,11$, 12], and DRB $1 * 03$ in Famoori Arabs residing in Fars province, have been reported as the most abundant alleles [12].

Previous studies indicated that alleles of DRB $1 * 08$, $\mathrm{DRB} 1 * 09$, and $\mathrm{DRB} 1 * 12$ have the least frequency among Iranian ethnic groups [4-6, 11-15]. These studies are almost consistent with our findings regarding the Gilak race, except that HLA-DRB1*09 was not observed in any participant. In a study conducted in Mashhad, no alleles of HLA-DRB $1 * 08$ and -DRB1*09 were observed in any of the studied individuals [13]. Interestingly, HLA-B*40 and HLA-B*51 were reported as the most abundant alleles in the Baloch tribes and Yazd population of Iran, respectively [9]. A study was conducted on Iranian Zoroastrian immigrants to Karachi, Pakistan, and Gujarat, India. This migration has probably occurred after the Arab invasion in the 9th century. Like the Iranian population, HLA-B*35 and DRB1*11 were found as the highest frequent alleles [16]. A*02 was reported as the most common allele in the neighboring countries or countries with the Caucasian origin, such as Italy $(0.254)$ [9], Crete in Greece (0.255), Turkey $(0.302)^{1}$, Pakistan (Baloch 0.135), and Morocco (0.178) [17].

A high frequency of $\mathrm{B}^{*} 35$ was found in Turkey (0.204), Greece (Crete $=0.244)$, Italy $(0.159)^{1}$, and Pakistan $($ Baloch $=0.138)$ [9]. DRB1*11 has the highest allele frequency in Iran, Syria, Lebanon, and Jordan as well as the second most common allele in Turkey, the third and fourth in Austria and Tunisia, and the sixth in the Saudi Arabia and France. This allele is detected with minor frequencies in China and Korea [21]. The frequency of DRB1*11 in Iranian ethnics, including Charmahal and Bakhtiyari, Yazd, Mashhad, and Fars are 16\%, 24.4\%, $24.8 \%, 24.8 \%$, and $25 \%$, respectively $[2,4,6,18]$. It is $2 \%$ in Scandinavian countries $[22,23]$. In East Asian 1. http://www.allelefrequencies.net/ countries such as Japan, China, and South Korea, the frequencies are $2.9 \%, 4.4 \%$, and $5.0 \%$, respectively [24, 25]. This allele frequency in Eastern Europe countries including Slovakia [24] Bulgaria [26], and Croatia [27] are $14.6 \% 16.4 \%$, and $18.2 \%$, respectively. While in Greece, Turkey, Spain, North India, Macedonia and Italy are $15 \%, 15.9 \%, 18 \%, 19 \%, 24.8 \%$, and $25 \%$, respectively $[19,20,28-30]$.

In this study, the most common haplotypes for HLA-A, -B and -DR were A02:B35:DRB01 (9.1\%), A68:B49:DRB14 (6.2\%), and A11:B51:DRB04 (5.1\%), respectively. This finding was similar in most Iranian ethnics except Baloch ecthnic and the population of Yazd Province [2, 9]. The obtained data revealed similarities between neighboring countries, common origin, and Caucasians (Figure 4 \& Table 5).

HLA typing provides information for anthropological studies to identify autoimmune diseases. It also helps in planning for the development of unrelated donor centers for stem cell transplantation [3]. The association between the prevalence of Rheumatoid Arthritis (RA) in different societies and the frequency of DRB1*01 [31] is already well recognized. Moreover, the prevalence of DRB $1 * 01$ in the Gilak ethnic is remarkable (compared to other cities). Thus, it can be hypothesized that the prevalence of RA in this ethnic group is high. It is suggested that the epidemiology of RA be investigated in this ethnic and compared with other regions of Iran. The study limitations included the lack of funding and limited access to the samples.

Determining HLA allele frequencies among different ethnic groups helps in planning more precise designs and developing stem cell donation centers. In addition, it can be beneficial for finding suitable donors for patients requiring stem cell transplantation. Despite some differences, there was a great similarity between the frequency of alleles of the Gilak ethnic and the rest of the Iranian population. Considering the high frequency of DRB1*01 allele in Gilak ethnic, it is suggested that the rate of this allele be investigated in terms of rheumatoid arthritis in this ethnic group.

\section{Ethical Considerations}

\section{Compliance with ethical guidelines}

The study was approved by the Research Ethics Committee of Immunology, Allergy and Asthma Research Institute, Tehran University of Medical Sciences (Code: 
IR.TUMS.IAARI.REC.1393.26486). The written informed consents were obtained from all study participants.

\section{Funding}

This study was supported by Tehran University of Medical Sciences (grant No. 93-02-40-26486).

\section{Authors contributions}

Conceptualization: All authors; Methodology: All authors, Investigation: Mansour Arab; Writing-original draft: All authors; Writing-review \& editing: All authors; Resources: All authors; and Supervision: Maryam Nourizadeh.

\section{Conflict of interest}

The authors declared no conflict of interest.

\section{References}

[1] Hajjej A, Almawi WY, Arnaiz Villena A, Hattab L, Hmida $\mathrm{S}$. The genetic heterogeneity of Arab populations as inferred from HLA genes. PLOS One. 2018; 13(3):e0192269. [DOI:10.1371/journal.pone.0192269] [PMID] [PMCID]

[2] Nikbin B, Nicknam MH, Hadinedoushan H, Ansaripour B, Moradi B, Yekaninejad M, et al. Human Leukocyte Antigen (HLA) class I and II polymorphism in Iranian healthy population from Yazd Province. Iranian Journal of Allergy, Asthma and Immunology. 2017; 16(1):1-13. [PMID]

[3] Rubinstein P, Rosenfeld R, Adamson JW, Stevens CE. Stored placental blood for unrelated bone marrow reconstitution. Blood Journal. 1993; 81(7):1679-90. [PMID]

[4] Esmaeili A, Rabe SZT, Mahmoudi M, Rastin M. Frequencies of HLA-A, B and DRB1 alleles in a large normal population living in the city of Mashhad, Northeastern Iran. Iranian Journal of Basic Medical Sciences. 2017; 20(8):940-3. [PMID] [PMCID]

[5] Shaiegan M, Yari F, Abolghasemi H, Bagheri N, Paridar M, Heidari A, et al. Allele frequencies of HLA-A, B and DRB1 among people of Fars ethnicity living in Tehran. Iranian Journal of Blood and Cancer. 2011;3(4):55-9.

[6] Amirzargar A, Mytilineos J, Farjadian S, Doroudchi M, Scherer S, Opelz G, et al. Human Leukocyte Antigen class II allele frequencies and haplotype association in Iranian normal population. Human Immunology. 2001; 62(11):1234-8. [DOI:10.1016/S0198-8859(01)00320-2]

[7] Farjadian S, Moqadam F, Ghaderi A. HLA class II gene polymorphism in Parsees and Zoroastrians of Iran. International Journal of Immunogenetics. 2006; 33(3):185-91. [DOI:10.1111/j.1744-313X.2006.00594.x] [PMID]

[8] Shahsavar F, Varzi AM, Ahmadi SAY. A genomic study on distribution of Human Leukocyte Antigen (HLA)-A and HLA-B alleles in Lak population of Iran. Genomics Data.
2017; 11:3-6. [DOI:10.1016/j.gdata.2016.11.012] [PMID] [PMCID]

[9] Farjadian S, Naruse T, Kawata H, Ghaderi A, Bahram S, Inoko $\mathrm{H}$. Molecular analysis of HLA allele frequencies and haplotypes in Baloch of Iran compared with related populations of Pakistan. Tissue Antigens. 2004; 64(5):581-7. [DOI:10.1111/j.1399-0039.2004.00302.x] [PMID]

[10] Sayad A, Akbari MT, Mehdizadeh M, Movafagh A, Hajifathali A. The association of HLA-Class I and class II with Hodgkin's Lymphoma in Iranian Patients. BioMed Research International. 2014; 2014(231236):1-5. [DOI: 10.1155/2014/231236] [PMID] [PMCID]

[11] Khazaei H, Aghamohammadi A, Rezaei N, Nikbin B, Khosravi M, MiriMoghaddam I. Major histocompatibility complex class I and II antigens frequencies in Baloch ethnic group living in the southeast region of Iran. Transplantation Proceedings; 2004; 36(5):1302-4. [DOI:10.1016/j.transproceed.2004.05.061]

[12] Farjadian S, Ota M, Inoko H, Ghaderi A. The genetic relationship among Iranian ethnic groups: An anthropological view based on HLA class II gene polymorphism. Molecular Biology Reports. 2009; 36(7):1943. [DOI:10.1007/s11033-0089403-4] [PMID]

[13] Sarafnejad A, Khosravi F, Alimoghadam K, Dianat S, Ansaripour B, Moradi B, et al. HLA class II allele and haplotype frequencies in Iranian patients with acute myelogenous leukemia and control group. Iranian Journal of Allergy, Asthma and Immunology. 2006; 5(3):115-20. [PMID]

[14] Khosravi F, Amirzargar A, Sarafnejad A, Nicknam MH, Alimoghadam K, Dianat S, et al. HLA class II allele and haplotype frequencies in Iranian patients with leukemia. Iranian Journal of Allergy, Asthma and Immunology. 2007; 6(3):13742. [PMID]

[15] Amanzadeh A, Amirzargar AA, Mohseni N, Arjang Z Aghamohammadi A, Shokrgozar MA, et al. Association of HLA-DRB1, DQA1 and DQB1 alleles and haplotypes with common variable immunodeficiency in Iranian patients. Avicenna Journal of Medical Biotechnology. 2012; 4(2):10312. [PMID] [PMCID]

[16] Mohyuddin A, Mehdi S. HLA analysis of the Parsi (Zoroastrian) population in Pakistan. Tissue Antigens. 2005; 66(6):691-5. [DOI:10.1111/j.1399-0039.2005.00507.x] [PMID]

[17] Piancatelli D, Canossi A, Aureli A, Oumhani K, Del Beato T, Di Rocco M, et al. Human Leukocyte Antigen -A, -B, and$\mathrm{Cw}$ polymorphism in a Berber population from North Morocco using sequence-based typing. Tissue Antigens. 2004 63(2):158-72. [DOI:10.1111/j.1399-0039.2004.00161.x] [PMID]

[18] Farjadian S, Ghaderi A. Iranian Lurs genetic diversity: An anthropological view based on HLA class II profiles. Iranian Journal of Immunology. 2006; 3(3):106-13. [PMID]

[19] Arnaiz Villena A, Benmamar D, Alvarez M, Diaz Campos N, Varela P, Gomez Casado E, et al. HLA allele and haplotype frequencies in Algerians: Relatedness to Spaniards and Basques. Human Immunology. 1995; 43(4):259-68. [DOI:10.1016/0198-8859(95)00024-X]

[20] Arnaiz Villena A, Iliakis P, González Hevilla M, Longás J, Gómez Casado E, Sfyridaki K, et al. The origin of Cretan populations as determined by characterization of HLA al- 
leles. Tissue Antigens. 1999; 53(3):213-26. [DOI:10.1034/ j.1399-0039.1999.530301.x] [PMID]

[21] Jazairi B, Khansaa I, Ikhtiar A, Murad H. Frequency of HLADRB1 and HLA-DQB1 alleles and haplotype association in Syrian population. Immunological Investigations. 2016; 45(2):172-9. [DOI:10.3109/08820139.2015.1131293] [PMID]

[22] Madsen M, Graugaard B, Lamm L, Josrgensen F, Kissmeyer Nielsen F. HLA-DR genes and antigens in the Danish population. A study of 500 unrelated Danes. Tissue Antigens. 1981; 18(4):258-69. [DOI:10.1111/j.1399-0039.1981. tb01390.x] [PMID]

[23] Rønningen KS, Spurkland A, Markussen G, Iwe T, Vartdal F, Thorsby E. Distribution of HLA class II alleles among Norwegian Caucasians. Human Immunology. 1990; 29(4):27581. [DOI:10.1016/0198-8859(90)90041-M]

[24] Wang FQ, Semana G, Fauchst R, Genetet B. HLA-DR and -DQ genotyping by PCR-SSO in shanghai Chinese. Tissue Antigens. 1993; 41(5):223-6. [DOI:10.1111/j.1399-0039.1993. tb02010.x] [PMID]

[25] Hashimoto $M$, Kinoshita T, Yamasaki M, Tanaka $H$, Imanishi $\mathrm{T}$, Ihara $\mathrm{H}$, et al. Gene frequencies and Haplotypic Associations within the HLA region in 916 unrelated Japanese individuals. Tissue Antigens. 1994; 44(3):166-73. [DOI:10.1111/j.1399-0039.1994.tb02375.x] [PMID]

[26] Ivanova R, Naoumova E, Lepage V, Djoulah S, Yordanov Y, Loste M, et al. HLA-DRB1, DQA1, DQB1 DNA polymorphism in the Bulgarian population. Tissue Antigens. 1996; 47(2):122-6. [DOI:10.1111/j.1399-0039.1996.tb02524.x] [PMID]

[27] Grubić Z, Ẑunec R, Naipal A, Kaŝtelan A, Giphart M. Molecular analysis of HLA class II polymorphism in Croatians. Tissue Antigens. 1995; 46(4):293-8. [DOI:10.1111/j.1399-0039.1995.tb02495.x] [PMID]

[28] Martinez Laso J, De Juan D, Martinez Quiles N, Gomez Casado E, Cuadrado E, Arnaiz Villena A. The contribution of the HLA-A, -B, -C and -DR, -DQ DNA typing to the study of the origins of Spaniards and Basques. Tissue Antigens. 1995; 45(4):237-45. [DOI:10.1111/j.1399-0039.1995.tb02446.x] [PMID]

[29] Arnaiz Villena A, Martínez Laso J, Gómez Casado E, Díaz Campos N, Santos P, Martinho A, et al. Relatedness among Basques, Portuguese, Spaniards, and Algerians studied by HLA allelic frequencies and haplotypes. Immunogenetics. 1997; 47(1):37-43. [DOI:10.1007/s002510050324] [PMID]

[30] Rani R, Fernandez Vina M, Stastny P. Associations between HLA class II alleles in a North Indian population. Tissue Antigens. 1998; 52(1):37-43. [DOI:10.1111/j.1399-0039.1998. tb03021.x] [PMID]

[31] Hill JA, Southwood S, Sette A, Jevnikar AM, Bell DA, Cairns E. Cutting edge: The conversion of arginine to citrulline allows for a high-affinity peptide interaction with the rheumatoid arthritis-associated HLA-DRB1* 0401 MHC class II molecule. The Journal of Immunology. 2003; 171(2):538-41. [DOI:10.4049/jimmunol.171.2.538] [PMID] 